\title{
Preliminary study on pathogenesis of bronchial asthma in children
}

\author{
Ya-Feng Ren ${ }^{1}$, Hong Li ${ }^{2}$, Xiao-Hong Xing ${ }^{2}$, Hai-Shan Guan ${ }^{2}$, Bo-Ai Zhang ${ }^{3}$, Chuan-Liang Chen ${ }^{4}$ and Jian-Hua Zhang ${ }^{5}$
}

\begin{abstract}
BACKGROUND: The etiology and pathogenesis of bronchial asthma remain unclear. This study is to investigate the risk factors related to bronchial asthma onset in children from genetics and immunology and preliminarily reveal the pathogenesis of bronchial asthma in children.
\end{abstract}

METHODS: Real-time quantitative PCR was adopted to detect the expression level of TRPV1 gene and mRNA and enzymelinked immunosorbent assay method to the total immunoglobulin E level and levels of IL-4, IL-5, and IFN- $\gamma$ in serum in peripheral venous blood for children in two groups. Logistic regression analysis was applied to analyze the most essential factors inducing bronchial asthma in children.

RESULTS: The mRNA level of TRPV1 in peripheral blood in the case group was higher than that in the control group $(P<0.01)$. The levels of IL-4, IL-5, and eosinophils in serum in the case group were markedly higher than those in the control group $(P$ $<0.01)$, while IFN- $\gamma$ level in the case group was lower than that in the control group $(P<0.01)$. The results of logistic regression analysis indicated that TRPV1 expression level, IL-4 level, and rs4790522 site mutation were the main risk factors inducing bronchial asthma in children.

CONCLUSION: The levels of TRPV1 gene expression and Th1/ Th2 cytokines have a close relationship with asthma onset in children, which provides theoretical evidences for molecular targeted treatment in children with bronchial asthma.

B ronchial asthma is a worldwide high-incidence disease. With the highest morbidity and gradually rising trend, it is also the most common chronic respiratory disease in childhood (1). Asthma not only does harm to children's physical and mental health, but also results in a heavy burden to patients' family and society (2). Currently, it has been verified by some studies that asthma is induced by the joint effect of multifactors including immunity, environment, and inheritance and so on $(3,4)$. However, the etiology and pathogenesis of the disease remain unclear. Therefore, it is of great significance for the patients and society to study the etiology and pathological mechanism of asthma.
The study of asthma candidate genes demonstrates that the characteristics of gene polymorphism for candidate genes are related to the susceptibility and severity of asthma in children, but still there exist some significant ethnic differences(5). Therefore, the study on the differences of asthma in different races and regions is helpful to early diagnosis, prevention, and treatment of it. In recent years, with the deep understanding of the pathogenesis of bronchial asthma respiratory inflammation, the signal regulatory effect of transient receptor potential cation channel, subfamily $\mathrm{V}$, member 1 (TRPV1) gene on asthma also becomes a research focus. TRPV1, as a V subfamily (TRPV1-TRPV6) member in nonselective cation channel superfamily, shows a relatively extensive expression in mammal respiratory system. Studies have indicated that TRPV1 distributes in respiratory tract and coexists with $\mathrm{P}$ substance in the trachea epithelial tissues (6). Clark (7) found that in the model of abdominal sepsis induced by lipopolysaccharide, after the TRPV1 was deleted, the levels of interferon- $\alpha$ (TNF- $\alpha$ ) and nitric oxide (NO) in mouse peritoneal exudates were significantly increased, which showed that TRPV1 might play a protective role in some inflammation. However, it is still unclear about what the mechanism of inhibiting the inflammation effect mediated by TRPV1 is. Some studies indicate that TRPV1 may be the important signal-regulating molecule participating in the inducing children asthma (8), but this statement needs to be confirmed. This study aims to discuss the relationship between the expression level of TRPV1 gene as well as the polymorphism of single nucleotide polymorphism (SNP) sites and the susceptibility of childhood asthma. Through selecting the untranslated regions (3'-UTR) that are closely related to the activity of regulation and transcription as the target segment, studying the case-control and related risk factors of asthma analyzing the asthma pathogenesis in the aspects of immunology and genetics, the effect of TRPV1 gene and relevant cytokines on the pathogenesis of asthma was preliminarily explored, which provided certain theoretical evidences and practical guidance for searching gene-targeted therapy and immunological therapy for inhibiting the inflammatory reaction in the respiratory tract. 


\section{RESULTS}

\section{Results of TRPV1 Gene Expression Level and SNP Site Analysis}

The normality test for the relative quantification results of TRPV1 real-time quantitative (RQ) PCR indicated that the data of the case group neither satisfied the normal distribution nor met the precondition of parametric test. The Wilcoxon rank-sum test is summarized in Table 1, which shows that the TRPV1 expression level in the case group was obviously different to that in the control group $(P<0.01)$. The TRPV1 expression level in the peripheral blood of children with asthma was higher than that of healthy children.

By $\chi^{2}$ test and Fisher's exact test analyses, it was indicated that there was a significant difference in the genotype distribution of the two SNP sites (rs4790521 and rs4790522) between the case group and the control group. Moreover, the sequencing and genotyping results of rs4790521 site showed that the $\mathrm{C}$ allele frequency in the case group was obviously higher than that in the control group $(P<0.05)$, while the genotyping results of rs4790522 site indicated that there were significant differences in the CC, AC, and AA genotype distributions between the two groups. Meanwhile, the $C$ allele frequency in the case group was obviously higher than that in the control group $(P<0.05$, Table 2$)$.

Determination of Total Immunoglobulin E (IgE) Level and Results of Eosinophils (EOS) Counting

Upon analyses, the total IgE level difference between the case group and control group showed that there was no statistical

Table 1. Comparison of the TRPV1 mRNA expression level between the case group and the control group

\begin{tabular}{lcccccccc}
\hline & & \multicolumn{9}{c}{$n$ fractile } & & & \\
\cline { 3 - 6 } Group & $N$ & P25 & P50 & P75 & P90 & Range & $Z$ & $P$ \\
\hline Case & 75 & 3.80 & 6.04 & 7.59 & 9.22 & $-6.63-9.92$ & & \\
Control & 65 & 0.42 & 2.42 & 5.37 & 5.74 & $-4.05-8.51$ & & $<0.01$ \\
\hline
\end{tabular}

Table 2. Comparison of the genotype distribution of two SNP sites (rs4790521 and rs4790522) between the case group and the control group

\begin{tabular}{|c|c|c|c|c|c|c|c|}
\hline \multirow[b]{2}{*}{ SNP site } & \multirow[b]{2}{*}{ Group } & \multirow[b]{2}{*}{$n$} & \multicolumn{3}{|c|}{ Genotype distribution $n(\%)$} & \multicolumn{2}{|c|}{ Allele $n(\%)$} \\
\hline & & & CC & $\mathrm{CT}$ & TT & C & $\mathrm{T}$ \\
\hline \multirow[t]{6}{*}{ rs4790521 } & Case & 75 & $\begin{array}{c}16 \\
(21.33)\end{array}$ & $\begin{array}{c}27 \\
(36.00)\end{array}$ & $\begin{array}{c}32 \\
(42.67)\end{array}$ & $\begin{array}{c}59 \\
(39.33)\end{array}$ & $\begin{array}{c}91 \\
(60.67)\end{array}$ \\
\hline & Control & 65 & $7(10.77)$ & $\begin{array}{c}21 \\
(32.31)\end{array}$ & $\begin{array}{c}37 \\
(56.92)\end{array}$ & $\begin{array}{c}35 \\
(26.92)\end{array}$ & $\begin{array}{c}95 \\
(73.08)\end{array}$ \\
\hline & $\chi^{2}$ & & \multicolumn{3}{|c|}{3.94} & \multicolumn{2}{|c|}{4.81} \\
\hline & \multicolumn{2}{|l|}{$P$} & \multicolumn{3}{|c|}{0.14} & \multicolumn{2}{|c|}{$<0.05$} \\
\hline & & & \multicolumn{3}{|c|}{ Genotype distribution $n(\%)$} & \multicolumn{2}{|c|}{ Allele $n(\%)$} \\
\hline & Group & $n$ & CC & $A C$ & AA & C & A \\
\hline \multirow[t]{4}{*}{ rs4790522 } & Case & 75 & $\begin{array}{c}41 \\
(54.67)\end{array}$ & $\begin{array}{c}30 \\
(40.00)\end{array}$ & $\begin{array}{c}4 \\
(5.33)\end{array}$ & $\begin{array}{c}112 \\
(74.67)\end{array}$ & $\begin{array}{c}38 \\
(25.33)\end{array}$ \\
\hline & Control & 65 & $\begin{array}{c}22 \\
(33.85)\end{array}$ & $\begin{array}{c}37 \\
(56.92)\end{array}$ & $\begin{array}{c}6 \\
(9.23)\end{array}$ & $\begin{array}{c}81 \\
(62.31)\end{array}$ & $\begin{array}{c}49 \\
(37.69)\end{array}$ \\
\hline & $\chi^{2}$ & & \multicolumn{3}{|c|}{6.18} & \multicolumn{2}{|c|}{4.97} \\
\hline & $P$ & & \multicolumn{3}{|c|}{$<0.05$} & \multicolumn{2}{|c|}{$<0.05$} \\
\hline
\end{tabular}

significance. The EOS count in the peripheral blood of the case group was obviously larger than that of the control group. Meanwhile, there existed a significant difference $(P<0.05)$. This may be the result of the exacerbation in the case group (Table 3).

\section{Detection of Serum Cytokine IL-4, IL-5, and IFN- $\gamma$}

Compared with control group, the levels of IL- 4 and IL- 5 in the case group were markedly higher, while the level of IFN- $\gamma$ was significantly lower $(P<0.05$, Table 4$)$.

\section{Multivariate Logistic Regression Analysis of Factors Related to Childhood Asthma}

The results of the above-mentioned tests indicated that the differences in TRPV1 mRNA expression level, allele frequency of rs4790521 and rs4790522 polymorphic sites, EOS count in peripheral blood as well as the levels of IL-4, IL-5, and IFN- $\gamma$ between the two groups showed statistical significances $(P<0.05)$. However, the total IgE level showed that there was no difference between the case group and the control group $(P>0.05)$. The logistic regression analysis was performed on the factors with the difference showing statistical significance, which helped to gradually screen variables. Finally, the results indicated that the TRPV1 mRNA level, IL-4 level, and rs4790522 locus mutation were the risk factors of childhood asthma (Table 5).

\section{DISCUSSION}

The transient receptor potential vanilloid channels (TRPVs) have an extensive expression in respiratory system. They not only express a relatively higher permeability to $\mathrm{Ca}^{2+}$, but also participate in the regulation of many important physiological functions, such as the release of airway inflammatory factors and the contraction of airway smooth muscle. In addition, they

Table 3. Comparison of the total IgE level and ESO count in peripheral blood between the case group and the control group

\begin{tabular}{lcccc}
\hline & \multicolumn{4}{c}{ Detection index } \\
\cline { 2 - 5 } Group & $\begin{array}{c}\text { Normal } \\
\text { expression }\end{array}$ & $\begin{array}{c}\text { Expression } \\
\text { increase }\end{array}$ & $N$ & EOS $\left(\times 10^{6} /\right)$ \\
Case group & $23(30.67 \%)$ & $52(69.33 \%)$ & 75 & $431 \pm 108$ \\
Control & $23(35.38 \%)$ & $42(64.62 \%)$ & 65 & $169 \pm 67$ \\
group & & & & \\
$T$ value & $\chi^{2}=0.35$ & $T=8.69$ \\
$P$ value & $P=0.55$ & $P<0.01$ \\
\hline
\end{tabular}

Table 4. Comparison of IL-4, IL-5, and IFN- $\gamma$ levels between the case group and the control group $(x \pm s)$

\begin{tabular}{lcccc}
\hline Group & $n$ & $\mathrm{IL}-4(\mathrm{ng} / \mathrm{l})$ & $\mathrm{IL}-5(\mathrm{ng} / \mathrm{l})$ & $\mathrm{IFN}-\gamma(\mathrm{ng} / \mathrm{l})$ \\
\hline Case group & 75 & $157.58 \pm 24.16$ & $46.31 \pm 11.73$ & $33.28 \pm 7.22$ \\
Control group & 65 & $69.47 \pm 13.38$ & $25.58 \pm 7.09$ & $56.45 \pm 12.47$ \\
$T$ & & 16.39 & 8.06 & 9.14 \\
$P$ & & $<0.01$ & $<0.01$ & $<0.01$ \\
\hline
\end{tabular}


Table 5. Logistic regression analysis of the related factors of childhood asthma

\begin{tabular}{lccccc}
\hline Selected variables & $\begin{array}{c}\text { Regression } \\
\text { coefficient }\end{array}$ & Wald & $P$ & OR & \multicolumn{1}{c}{$95 \% \mathrm{Cl}$} \\
\hline TRPV1 mRNA level & 0.42 & 3.74 & 0.04 & 1.52 & $1.29-2.67$ \\
MAF of rs4790522 & 2.21 & 7.32 & 0.01 & 9.12 & $6.73-15.04$ \\
IL-4 level & 1.23 & 5.17 & 0.03 & 3.44 & $1.37-6.09$ \\
\hline
\end{tabular}

play a critical role in the development of respiratory diseases including asthma, chronic obstructive pulmonary diseases, allergic rhinitis, and others (9). Therefore, some researchers believed that the polymorphism of the TRPV gene may be associated with the hereditary susceptibility of asthma (10). As a sort of TRPVs, TRPV1 was proved to have a strong association with respiratory diseases by studies $(11,12)$. In a study of the effect of TRPV1 3'-UTR gene polymorphism on the asthma susceptibility of Han children in Beijing, Wang (13) found that the allozygote CC of rs4790521 SNP was closely associated with childhood asthma, and it was the important risk factor in affecting the susceptibility of childhood asthma $(P<0.05)$. The experiment by Nassini (14) verified that the transient receptor potential vanilloid 1 (TRPV1) or its excitation may induce the neurogenic inflammatory reaction in respiratory tract, while the inflammatory reaction caused by the excitation of single TRPV1 was not neurogenic, thus a speculation was put forward by them that the non-neurogenic TRPV1 in the respiratory tract may lead to airway inflammation reaction. There also exist studies showing that TRPV1 is regulated by inflammatory mediators, but the relationship between the TRPV1 and inflammatory mediators still is not clear (15). This research showed that the expression level of TRPV1 mRNA in the peripheral blood of children with asthma was higher than that of healthy children. The analysis of gene frequency of rs4790521 and rs4790522 SNP sites indicated that, compared with control group, they both showed significant differences $(P<0.05)$, which implies that TRPV1 plays a certain promotional role in the onset process of childhood asthma. One of the main features of bronchial asthma is the chronic allergic airway inflammation that participated by EOS and Th cell and so on $(16,17)$. This study took on a further verification that the expression of TRPV1 gene induced or promoted the inflammatory reaction of asthma.

Bronchial asthma is not caused by reversible bronchial smooth muscle spasm, but is a chronic inflammatory disease participated by inflammatory cells and medium including EOS, mast cells, T cells (18). Recently, some scholars have put forward that the imbalance of Th1/Th2 cytokines is a vital mechanism for asthma onset $(19,20)$, which mainly shows that Th2 cells contribute to hyperfunction, and, the secretion of Th2 cytokines, such as IL- 4 and IL- 5 increases, while that of Th1 cytokines, such as IFN- $\gamma$ decreases. Moreover, IL- 4 and IL-5 are able to lead to airway local EOS chronic inflammation and generate airway hyper-reactivity, thus resulting in asthma. Some studies found that, by secreting IFN- $\gamma$, Th1 cells can inhibit the synthesis of IgE. By secreting IL-4, Th2 cells, in contrast, can induce B cells to synthesize IgE (21). EOS, as the major effector cell in allergic asthma, is the main marker of asthma, which also plays a vital role in allergic inflammatory disease (22). EOS gap-associated protein can directly damage the airway epithelium, and result in the contraction of airway smooth muscle and the enhancement of airway responsiveness. IL-5 is able to activate a series of EOS reaction, combine with the EOS receptor and play an important role in adjusting EOS generation, differentiation, aggregation, activity, and prolonging mature EOS lifetime (23). This study showed that the levels of serum IL-4 and IL-5 as well as EOS in the case group were obviously higher than those in the control group $(P<0.01)$, while the level of IFN- $\gamma$ was lower than that in the control group $(P<0.01)$. The IgE level showed that there was no statistical significance. Therefore, it was indicated that there existed marked inflammatory response and imbalance of Th1/ Th2 cytokines in children of the case group. Meanwhile, the logistic regression analysis of related factors of childhood asthma indicated that the rs 4790522 site mutation (odds ratio $(\mathrm{OR})=9.12,95 \%$ confidence interval $(\mathrm{CI}): 6.73-15.04)$, IL-4 $(\mathrm{OR}=3.44,95 \%$ CI: 1.37-6.09) as well as TRPV1 mRNA level $(\mathrm{OR}=1.52,95 \% \mathrm{CI}: 1.29-2.67)$ were the risk factors of asthma. Furthermore, this result suggested that both hereditary factors and immunological factors played important roles in the asthma onset of children, and the three factors may promote the condition deterioration for patients with asthma.

\section{METHODS}

\section{Subjects of the Study}

According to the survey and sample size calculation parameter setting by the staff of People's Hospital of Zhengzhou, we calculated the sample size parameters of the two groups. The hospitalized asthmatic children in People's Hospital of Zhengzhou from August 2011 to April 2012 were selected as the case group ( 75 cases, with 49 boys and 26 girls), aged from 2 to $12 \mathrm{y}$ with an average age of $5.6 \pm 3.5 \mathrm{y}$. The proportion "P" of the subjects was $5 \%$ of the total child asthma patients in Henan Province, with the anticipation error $e( \pm 0.05)$. The CI was set within $95 \%$. The parameters in the control group were the same as those in the case group, except for $P=4.5 \%$. The sample size calculation formula was obtained by the known percentage of random sampling sample size $n=Z^{2} P(1-P) / e^{2}(24)$, wherein $\mathrm{Z}$ was the required amount of $95 \%$ CI 1.96 . The sample size of the case group was calculated as 72.99. The sample size of the control group was 66.03. On this basis, the case group was collected. The children (65 cases, with 42 males and 23 females) who had passed the physical examination in this hospital were selected as the control group, aged from 2 to $12 \mathrm{y}$ with an average age of $6.3 \pm 4.1 \mathrm{y}$. The balanced age and gender distribution showed the comparability between the case group and the control group.

\section{Inclusion and Exclusion Criteria}

Case group. Outpatients with severe asthma were diagnosed by two senior asthma specialists and included. In addition, their medical records and so forth were reviewed to confirm the compliance with asthma diagnostic criteria (25). The patients with serious heart, liver, kidney, organic disease and other chronic lung disease and atopic disease were excluded.

Control group. All of the children had neither family history nor personal history of allergic response or history of asthma in this group.

The subjects involved in this study were the Han nationality children from Henan Province. All the subjects who participated in this study obtained the agreements from their guardians and signed the informed consent. Moreover, this project was also approved by the Chinese Ethics Committee of Registering Clinical Trials. 


\section{Sample Collection}

Three milliliters of peripheral venous blood were extracted from each child in the case group and control group under the condition of fasting in the morning. Among which, 1-ml peripheral venous blood was added to ethylene diamine tetraacetic acid disodium salt (EDTA-K2) (purchased from Shanghai Haling Biological Technology, Shanghai, China) for anticoagulation and stored at $-20{ }^{\circ} \mathrm{C}$ in the refrigerator (purchased from Qingdao Haier, Qingdao, China), which was used for extracting the total RNA. The rest of the blood were used for making blood films and then prepared for serum. After standing $1 \mathrm{~h}$ at room temperature, then, centrifugated for $10 \mathrm{~min}$ at $2,000 \mathrm{~g}$, and the obtained serum was cryopreserved for inspection in the refrigerator (purchased from Qingdao Haier) at $-70{ }^{\circ} \mathrm{C}$.

\section{The TRPV1 mRNA Level of Subjects Detected by RQ-PCR}

A total RNA rapid extraction kit (purchased from Dalian Treasure Biological Engineering, Dalian, China) was used for extracting RNA from the lymphocytes in the 1-ml peripheral blood with EDTA-K2 anticoagulation. Then the oligo DT was used as the primer and the total RNA was applied as the template. Finally, with the role of reverse transcriptase, the cDNA was synthesized pursuant to the operation manual.

According to TRPV1 3'-UTR target gene sequence in GenBank, a pair of primer was designed by GENETOOL software (GeneBio, Geneva, Switzerland), which was synthesized by Shanghai Sangon Biological Engineering Technology Service (Shanghai, China). That is the sense primer sequence of TRPV1 mRNA was 5'-GGCTGTCTTCATCATCCTGCTGCT-3', while the reverse primer sequence was 5'-GTTCTTGCTCTCCTGTGCGATCTTGT-3', and the size of its PCR product was $117 \mathrm{bp}$.

Using glyceraldehyde-3-phosphate dehydrogenase (GAPDH) as the reference gene, GAPDH gene was synthesized by RQ-PCR. The sense primer sequence was 5'-TGCACCACCAACTGCTTAGC-3', while the reverse primer sequence was 5'-GGCATGGACTGTGGTCATGAG-3', and the size of the product was $87 \mathrm{bp}$. Moreover, the reaction cycle parameters were: initial denaturation was at $94{ }^{\circ} \mathrm{C}$ for $10 \mathrm{~min}$; then denaturation at $94{ }^{\circ} \mathrm{C}$ for $30 \mathrm{~s}$, afterward, annealing at $56{ }^{\circ} \mathrm{C}$ for 30 $\mathrm{s}$, finally elongation at $72{ }^{\circ} \mathrm{C}$ for $30 \mathrm{~s}$, which conducted 40 cycles in total. In addition, the elongation was at $72^{\circ} \mathrm{C}$ for $7 \mathrm{~min}$ after 30 cycles again. MY CYCLER (Bio-Rad, CA) PCR instrument was used for PCR reaction, and three multiple pores were made in all samples. The Wilcoxon rank-sum test was adopted for the fiducial interval range and relative quantification. Furthermore, $2-\Delta \Delta C \mathrm{C}$ (Licak) method was used for the comparison of relative expression levels in TRPV1 for children in the case group and control group.

\section{Selection and Detection of the Target SNP Site}

The Chinese $(\mathrm{CHB}+\mathrm{JPG})$ TRPV1 gene $3^{\prime}$-UTR region SNPs in Haploview4.1 (Open Source Development Network, Tokyo, Japan) were downloaded and the SNP database in NCBI was referred (US National Library of Medicine, Bethesda, MD). macrophage activating factor $(\mathrm{MAF})>5 \%$ and $\mathrm{r} 2>0.8$ were set up to screen the tag SNP of the $3^{\prime}$-UTR of this gene. SNP detection: direct sequencing was conducted on PCR reaction product; sequencing primers were the same as PCR primers; the target gene sequence was detected in Shanghai Invitrogen Company (Shanghai, China), with the utilization of $\mathrm{ABI} 3730 \mathrm{XL}$ sequencer.

\section{Cell Counting of Blood Film and Determination of Serum Total IgE Level}

The blood film was placed on the cell counting plate. After standing $24 \mathrm{~h}$ at room temperature and the process of Wright staining (Wright's stain), the number of EOS was counted under the higher power lens with 400 times, counting 200 cells in each film. Meanwhile, the double antibody sandwich enzyme-linked immunosorbent assay (ELISA) method was applied to determine the serum total IgE level. Furthermore, the ELISA kit was provided by Chinese Cluster Technology (Hangzhou, China) and the operation was taken strictly in accordance with the specification.

\section{Cytokine Detection}

The ELISA method was used for determining the levels of serum interleukin-4 (IL-4), interleukin-5 (IL-5), and interferon- $\gamma$ (IFN- $\gamma$ ).
Coincidently, the reagent was also provided by Chinese Cluster Technology. At the same time, all the detection procedures were strictly consistent with the operation manual. The detailed procedures are as follows: Firstly, taking out the plates from the bag that balanced into room temperature, the rest was put back in the refrigerator at $4{ }^{\circ} \mathrm{C}$ after wellsealed. Except for the blank well, the specimen $(100 \mu \mathrm{l} /$ well $)$ as well as the standard substances in different concentrations $(100 \mu \mathrm{l} /$ well $)$ was added into the wells, respectively, afterward, the reaction wells were sealed by the gummed paper. With the warm bath at $37^{\circ} \mathrm{C}$ for $90 \mathrm{~min}$, the plates were then washed four to six times. Afterwards, the plates were dried with the assistance of filter papers. Except for the blank well, all the other wells were mixed with biotin antibody $(100 \mu \mathrm{l} /$ well $)$, with the reaction at $37^{\circ} \mathrm{C}$ for $30 \mathrm{~min}$. After washing the plate four times, 20 -min incubation away from light was performed. Then, each hole was added successively with $100-\mu \mathrm{l}$ stop buffer, mixing, finally the reaction was ended. Therewith, putting the reaction plate into a microplate reader (BioTek Instruments, Burlington, VT), the OD450 value was measured. In the end, the corresponding cytokine content was counted pursuant to the OD value of samples, then multiplying by dilution ratio of the samples. The actual content of each sample cytokine was obtained. Ultimately, the mean value was regarded as the relative amount.

\section{Data Statistics and Analysis}

The mean value $\pm \mathrm{SD}(x \pm s)$ was used to represent the detected data in each experimental group. SPSS statistical software (version 16.0; SPSS, Chicago, IL) was used to analyze the experimental data. At $P<$ 0.05 , the difference showed a statistical significance.

\section{ACKNOWLEDGMENTS}

The authors thank the Medical Engineering Technology and Data Mining Institute of Zhengzhou University. This institute has given the authors a great deal of help in experimental guidance and advice. Then, the authors would like to thank the First Affiliated Hospital of Zhengzhou University. This hospital offered the authors a perfect experimental base and data sources. Finally, the authors thank Zhang, the director of the institute, and all of the staff. Without their joint efforts, discussion on this subject would have not been possible.

Y.-F.R. conceived the experiments. H.L. and B.-A.Z. designed and drafted the manuscript. X.-H.X. acquired the data and performed the experimental statistical analysis. H.-S.G. conceived the study, participated in its design, and helped to draft the manuscript. C.-L.C. and J.-H.Z. analyzed the data and were involved in study supervision. All authors read and approved the final manuscript.

\section{STATEMENT OF FINANCIAL SUPPORT}

This project was supported by the Science and Technology Cooperation Projects in Henan Province (grant 122106000042), which is organized by Henan and other provinces' universities and well-known experts. The authors were supported by the Science and Technology Open Cooperation Projects in 2013 in Henan Province (grant 132106000064).

Disclosure: The authors declare that there are no conflicts of interest regarding the publication of this paper.

\section{REFERENCES}

1. James AL, Knuiman MW, Divitini ML, et al. Changes in the prevalence of asthma in adults since 1966: the Busselton health study. Eur Respir J 2010;35:273-8.

2. Ji M, Cai S. Nursing of bronchial asthma in children. J Nur Sci 2005;20: 68-70.

3. Marks GB. Environmental factors and gene-environment interactions in the aetiology of asthma. Clin Exp Pharmacol Physiol 2006;33:285-9.

4. Cheng Z, Wang J, Xing LH, et al. Relationship between child asthma and heredity. J App Clin Ped 2006;21:626.

5. Wang Q. Association Study in Air Pollutants, Genetic Variations of Candidate Genes, and Childhood Asthma. Beijing, China: Chinese Center for Disease Control and Prevention, 2010.

6. McLeod RL, Correll CC, Jia Y, Anthes JC. TRPV1 antagonists as potential antitussive agents. Lung 2008;186 Suppl 1:S59-65.

7. Clark N, Keeble J, Fernandes ES, et al. The transient receptor potential vanilloid 1(TRPV1) receptor protects against the onset of sepsis after endotoxin. FASEB J 2007;21:3747-55. 


\section{Articles $\mid$ Ren et al.}

8. Geppetti P, Materazzi S, Nicoletti P. The transient receptor potential vanilloid 1: role in airway inflammation and disease. Eur J Pharmacol 2006;533:207-14.

9. Mabalirajan U, Rehman R, Ahmad T, et al. Linoleic acid metabolite drives severe asthma by causing airway epithelial injury. Sci Rep 2013;3:1349.

10. Cantero-Recasens G, Gonzalez JR, Fandos C, et al. Loss of function of transient receptor potential vanilloid 1 (TRPV1) genetic variant is associated with lower risk of active childhood asthma. J Biol Chem 2010;285:27532-5.

11. McLeod RL, Fernandez X, Correll CC, et al. TRPV1 antagonists attenuate antigen-provoked cough in ovalbumin sensitized guinea pigs. Cough 2006;2:10.

12. Zhang G, Lin R-L, Wiggers M, Snow DM, Lee L-Y. Altered expression of TRPV1 and sensitivity to capsaicin in pulmonary myelinated afferents following chronic airway inflammation in the rat. J Physiol 2008;586:5771-86.

13. Wang Q, Bai X, Xu D, et al. TRPV1 UTR-3 polymorphism and susceptibility of childhood asthma of the Han Nationality in Beijing. J Hyg Res 2009;38:516-21.

14. Nassini R, Pedretti P, Moretto N, et al. Transient receptor potential ankyrin 1 channel localized to non-neuronal airway cells promotes non-neurogenic inflammation. PLoS ONE 2012;7:e42454.

15. Jia Y, Hong YG. Transient receptor potential vanilloid 1 (TRPV 1) and inflammatory pain. Chin Bulle Life Sci 2010;22:1259-63.
16. Holgate ST, Wilson JR, Howarth PH. New insights into airway inflammation by endobronchial biopsy. Am Rev Respir Dis 1992;145(2 Pt 2): S2-6.

17. Bousquet J, Chanez P, Lacoste JY, et al. Epsinophilic inflammation in asthma. N Engl J Med 1990;323:1033-9.

18. Zhao L. Effects of Xin Qin alevaire on lung function, EOS and IgE in patients with bronchial asthma. J Clin Med Pra 2013;17:25-7, 37.

19. Holgate ST. Innate and adaptive immune responses in asthma. Nat Med 2012;18:673-83.

20. Umetsu DT, McIntire JJ, Akbari O, Macaubas C, DeKruyff RH. Asthma: an epidemic of dysregulated immunity. Nat Immunol 2002;3:715-20.

21. Ngoc PL, Gold DR, Tzianabos AO, Weiss ST, Celedón JC. Cytokines, allergy, and asthma. Curr Opin Allergy Clin Immunol 2005;5:161-6.

22. Umetsu DT. Revising the immunological theories of asthma and allergy. Lancet 2005;365:98-100.

23. Karp M, Oker-Blom C. A streptavidin-luciferase fusion protein: comparisons and applications. Biomol Eng 1999;16:101-4.

24. Zhang GY. About determination of sample size in survey sampling. J Anhui Univ Sci Tech (Soci Sci) 2003;5:30-3.

25. Respiratory Group of Chinese Pediatric Society, Chinese Medical Association. Guideline for the diagnosis and optimal management of asthma in children. Chin J Pediatr 2008;46:745. 